\title{
Pós-estruturalismo e teoria do discurso: em torno de Ernesto Laclau
}

\author{
Fabricio Martinatto da Costa' \\ Everton Garcia da Costa $a^{2}$ \\ Gabriel Bandeira Coelho ${ }^{3}$
}

\author{
MENDONÇA, D.; RODRIGUES, L. P. (Org.). Pós-Estruturalismo \\ e Teoria do Discurso: em torno de Ernesto Laclau. 2. ed. Porto Alegre: \\ EDIPUCRS, 2014.
}

Ernesto Laclau foi, sem dúvida, um dos principais pensadores sociais que viveram entre o final do século XX e o início do século XXI. Da mesma forma, a Teoria do Discurso desenvolvida pelo autor, em parceria com a teórica política Chantal Mouffe $e^{4}$ apresenta-se como um dos principais modelos teóricos propostos nos últimos anos no âmbito das ciências humanas e sociais. Fundador, juntamente com Mouffe, da Essex School of discourse analysis, na Inglaterra, Laclau articula elementos do pós-estruturalismo, do (pós)marxismo, da psicanálise lacaniana e da filosofia heideggeriana, criando um poderoso e inovador modelo de análise social, o qual está ancorado em um vasto aparato de ferramentas conceituais.

Nesse sentido, não é demais afirmar que Pós-Estruturalismo e Teoria do Discurso: em torno de Ernesto Laclau é uma das principais obras lançadas no Brasil acerca da Teoria do Discurso e do pensamento do teórico político argentino. Organizada por Daniel de Mendonça e Leo Peixoto Rodrigues, a obra foi publicada, originalmente, em 2008, pela editora da Pontifícia Universidade Católica do Rio Grande do Sul (PUC-RS). Como o livro teve uma grande

I Bacharel em Direito. Mestrando em Sociologia na Universidade Federal de Pelotas (UFPEL). E-mail: fabriciomartinatto@gmail.com

2 Mestre em Ciências Sociais. Doutorando em Sociologia na Universidade Federal do Rio Grande do Sul (UFRGS). E-mail:eve.garcia.costa@gmail.com

3 Mestre em Sociologia pela Universidade Federal de Pelotas (UFPEL). Professor substituto de Relações Humanas do Instituto Federal Sul-rio-grandense, Campus Pelotas.E-mail: gabrielbandeiracoelho@yahoo.com.br

4 Laclau e Mouffe apresentam a Teoria do Discurso na obra Hegemony and socialist strategy: towards a radica democratic politics, publicada em 1985. 
recepção positiva no meio intelectual brasileiro, a referida editora encomendou uma segunda edição, lançada em 2014. No ano de sua precoce morte, ocorrida em 13 de abril de 2014, nada mais apropriado do que homenagear Ernesto Laclau a partir de uma divulgaçáo mais ampla da sua perspectiva teórica no Brasil, país cujos acontecimentos sociopolíticos têm demonstrado o potencial analítico da Teoria do Discurso para se (re)pensar alternativas às defasadas propostas teóricas apresentadas no cenário acadêmico brasileiro.

Pós-Estruturalismo e Teoria do Discurso conta com uma apresentação elaborada por Oliver Marchart (filósofo e sociólogo político austríaco, professor de Sociologia da Academia de Arte de Dusseldorf, e que também estudou na Essex School), com um prefácio escrito por Aletta Norval (teórica política sul-africana, diretora do Programa de Doutorado em Ideologia e Análise do Discurso e Codiretora do Centro de Estudos Teóricos, ambos da Universidade de Essex), e também com um posfácio escrito pelo próprio Laclau. Além disso, Pós-Estruturalismo e Teoria do Discurso possui, ainda, dez capítulos escritos por autores brasileiros e argentinos, todos de alguma forma relacionados ao pensamento laclauniano. Dessa forma, cabe apresentar - de forma breve cada um desses capítulos.

O primeiro Capítulo, intitulado Do estruturalismo ao pós-estruturalismo: entre fundamentar e desfundamentar, escrito por Daniel de Mendonça e Leo Peixoto Rodrigues - especialmente para esta segunda edição - é, indubitavelmente, o encaixe perfeito para esta coletânea. Nele, os autores destacam a proeminente discussão - que abre o século XX e se estende pelo século XXI com mais vigor - em torno da possibilidade de fundamentação e desfundamentação na ciência. A discussão dos autores é realizada a partir de um rigoroso e singular debate epistemológico que, por sua vez, levanta profundas questôes acerca de uma Filosofia da Ciência. O referido capítulo inicia salientando as principais características do conhecimento científico do século $\mathrm{XX}$, trazendo à tona, de forma pormenorizada, as reflexóes teóricas em torno do positivismo lógico - com seu fundamento bem delimitado (calcando a verdade, sobretudo na verificação do mundo empírico). Ressalta, também, os principais argumentos de Karl Popper no que tange ao seu critério de demarcação entre ciência e não ciência que, de modo geral, já denota uma "desfundamentação" da verdade objetiva que foi (e tem sido) dominante desde a 
Pós-estruturalismo e teoria do discurso: em torno de Ernesto Laclau | Fabricio Martinatto da Costa, Everton Garcia da Costa Gabriel Bandeira Coelho

emergência da ciência moderna. Ademais, os autores sublinham os contornos do estruturalismo francês, especialmente a linguística de Saussure - base epistemológica do estruturalismo - e a teoria social de Lévi-Strauss. Deste modo, encerram o capítulo elencando teses referentes à desconstrução de Derrida e a rota pós-estruturalista. Este último tema que, por seu turno, é essencial para a compreensão da filosofia política, alicerçada em bases pós-fundacionistas, de Ernesto Laclau.

No Capítulo 2, intitulado Em torno de Ernesto Laclau: estruturalismo e Teoria do Discurso, os organizadores fazem uma apresentação da obra. Conforme suas próprias palavras, o livro apresenta "[...] uma coletânea de textos destinada a demonstrar a relevância teórico-analítica do pensamento pós-estruturalista de Ernesto Laclau" (MENDONÇA; RODRIGUES, p. 54). Com efeito, a obra reúne trabalhos que abordam a Teoria do Discurso desenvolvida por Laclau nos mais diferentes campos, como a sociologia, a filosofia, a política, a educação, os estudos sobre identidade e diferença etc. $\mathrm{O}$ fato de a obra apresentar artigos de áreas do conhecimento táo variadas somente enfatiza o caráter abrangente da Teoria do Discurso. Além disso, trata-se de um efeito do próprio modo náo dogmatizado com o qual Laclau propôs suas categorias teóricas, sempre relacionadas a experiências práticas políticas. Isso possibilita um maior leque de aplicação e discussão da Teoria do Discurso laclauniana, abarcando temas que vão desde gestão escolar até discussôes sobre identidade e diferença. Ressalte-se, ainda, que, além de apresentar o livro, o capítulo também expóe alguns dos principais conceitos da teoria laclauniana, tais como discurso, elementos, articulação e hegemonia.

Por sua vez, o Capítulo 3, Discurso, política e sujeito na teoria da hegemonia de Ernesto Laclau, escrito por Joanildo A. Burity, tem por objetivo apresentar a Teoria do Discurso laclauniana, despindo-a, até certo ponto, da linguagem "técnica" empregada muitas vezes pelo teórico argentino. Nesse sentido, Burity organiza uma reflexão teórica acerca de alguns dos conceitos-chave da teoria de Laclau, tais como discurso, sentido, sujeito, hegemonia, articulação e antagonismo. Burity demonstra como Laclau articula essas noçóes ao desenvolver seu modelo teórico, além de destacar como elas estão intimamente vinculadas aos movimentos intelectuais com os quais Laclau dialoga: o marxismo, o estruturalismo e o pós-estruturalismo, a filosofia analítica e a heideggeriana, a linguística e o desconstrucionismo derridiano. 
No Capítulo 4, A impossibilidade da emancipação: notas a partir da Teoria do Discurso, Daniel de Mendonça faz uma crítica aos tradicionais discursos emancipatórios, tais como o religioso (que promete uma liberdade absoluta, a qual só pode ser alcançada por meio de um ser divino onisciente, onipresente e onipotente), por exemplo, ou o discurso marxista (para quem o proletariado era a classe universal destinada a organizar a derradeira revolução social, acabando com a dominaçáo da burguesia). De forma mais precisa, Mendonça apresenta as limitaçôes desses discursos emancipatórios - as quais impedem a emancipação de tornar-se um projeto político possível - e discute alternativas viáveis que conduzam a uma efetiva radicalização da democracia.

Em Universalismo e Particularismo: emancipação e democracia na Teoria do Discurso, Mirta Giaccaglia aborda a Teoria do Discurso de Laclau para pensar uma das características mais marcantes do mundo atual: a coexistência de processos de homogeneização e fragmentação nas relaçôes sociopolíticas. Para Giaccaglia, Laclau reinterpreta as tensóes existentes entre universalismo e particularismo, ao propor uma releitura da noçáo de hegemonia. Nesse sentido, a Teoria do Discurso considera o universal como um particular que acessa uma posição hegemônica e inicia uma disputa antagônica. As identidades, dessa forma, não se comportam como diferenças puras, isoladas entre si. Privilegiando-se a lógica equivalencial, defende-se que uma das identidades sociais esvazia parcialmente seu conteúdo para possibilitar a articulação com outros elementos do espaço político (outras identidades) e, destarte, assumir o lugar do universal, de maneira provisória. Adotar essa posição teórica evitaria que a defesa pelas diferenças, pretensão cara ao multiculturalismo, debandasse para atos discriminatórios que só veem os próprios valores como dignos de reconhecimento. A autora destaca a importância de se conceber as identidades como realidades híbridas e mestiças, em uma relação antagônica de constantes disputas e, além disso, de apontar o particular como ponto de partida de um universal relativo: eis as novas chaves teóricas para se "pensar e construir o devir” (MENDONÇA; RODRIGUES, p. 86). Tem-se a percepção de que o estudo de Giaccaglia, ao apresentar os principais elementos da perspectiva laclauniana - em especial a noção de "universalismo relativo" - para se pensar pluralismo identitário, conflitos indentitários, diferença e multiculturalismo, encoraja, ainda que indiretamente, um futuro debate sobre os pontos de toque e de separação da teoria de Laclau com outras abordagens que tratam da mesma temática, como os Estudos Culturais e os Estudos Feministas. 
Pós-estruturalismo e teoria do discurso: em torno de Ernesto Laclau | Fabricio Martinatto da Costa, Everton Garcia da Costa Gabriel Bandeira Coelho

No Capítulo 6, Luciana Marques - em Contribuiçôes da democracia radical e da Teoria do Discurso de Ernesto Laclau ao estudo da gestão da educação - apresenta um interessante estudo sobre a gestão democrática nas escolas públicas, apropriando-se da Teoria do Discurso como aporte analítico. Tem-se aqui uma demonstração de versatilidade da teoria de Laclau, visto que esta é adotada também para abordar temas relacionados à educação. Por intermédio de pesquisa empírica realizada nos Conselhos Escolares de três escolas municipais de Cabo de Santo Agostinho, Pernambuco, Marques infere que a política educacional deve ser entendida como uma formação discursiva destinada à construção de práticas sociais democráticas nas escolas públicas. Sem negar a (re)significação das políticas de democratização da gestão escolar pela agenda neoliberal, a autora argumenta que tais políticas são "instrumentos de construção da cidadania emancipatória” (MENDONÇA; RODRIGUES, p. 109). Sendo a política educacional uma prática discursiva, ela não é determinada $a$ priori por uma normatização, mas se materializa nas disputas agonísticas, nos conflitos que constroem a democracia radical dentro da escola com evidente repercussáo nos demais espaços sociais.

Seguindo na área educacional, Myriam Southwell aborda os processos educacionais à luz da Teoria do Discurso, no Capítulo 7 da obra, intitulado Em torno da construção de hegemonia educativa: contribuiçóes do pensamento de Ernesto Laclau ao problema da transmissão da cultura, Southwell aponta que o campo pedagógico deve superar a ideia de identidades sociais essenciais e preconcebidas. A teoria da hegemonia, assim, é adotada pela autora como modo alternativo de evidenciar as formas de construçáo do social, que se dariam mediante lutas hegemônicas de identidades sociais articuladas. Southwell realiza uma análise profunda da formaçáo contingente dos sistemas educacionais, argumentando que estes devem ser estudados não como se fossem uma unidade contínua que simplesmente reproduz os anseios de uma sociedade essencializada, mas como "resultado de uma articulação hegemônica" que "[...] articula elementos provenientes de setores dominantes e também de outros, e nesse resultado há uma discussão com as posições reprodutivas" (MENDONÇA; RODRIGUES, p. 144).

Carlos Pessoa, por seu turno, discute a atualidade da noção de hegemonia frente ao processo contemporâneo da globalização. Em Hegemonia em tempos de globalização, o autor traça um panorama histórico da noção de hegemonia, 
desde sua conceituação clássica, como um poder absoluto - portanto, não político - até sua concepção propriamente política, abordada por Antonio Gramsci e, finalmente, por Ernesto Laclau. Com efeito, Laclau percebe que o processo hegemônico é construído a partir de uma articulação de demandas particulares que, por sua vez, estabelece uma fronteira antagônica com o discurso dominante. A contribuição de tal construção teórica para a globalização, segundo Pessoa, é a de possibilitar sua aplicação em qualquer nível, seja local, regional ou global. Com essa verdadeira desterritorialização do conceito de hegemonia, as batalhas hegemônicas não estão mais restritas aos limites do Estado. Dessa forma, a noção de hegemonia se torna uma categoria analítica essencial para compreender a constituiçáo do político na era global.

Ronaldo Sales Jr., no nono Capítulo, intitulado Laclau e Foucault: desconstruçấo e genealogia, conforme as próprias palavras do autor, busca apresentar "[...] uma proposta de convergência teórico-metodológica entre a desconstrução laclauniana e a genealogia foucauldiana" (MENDONÇA; RODRIGUES, p. 163). Para tanto, elenca os seguintes pontos: "Foucault, discurso, poder e sujeito"; "Laclau, discurso, hegemonia e antagonismo social"; por fim, sublinha uma instigante síntese que aproxima Laclau e Foucault a partir do conceito de discurso. Além disto, Sales argumenta que sua orientação teórico-metodológica, neste artigo, está inscrita no campo da crítica da ideologia. $\mathrm{O}$ autor trata a ideologia, alicerçado epistemologicamente em Laclau e Foucault, como um fenômeno discursivo, salientando sua dimensão material, bem como a manutenção da ideia de que a própria ideologia faz referência a significados. De acordo com Sales, a Teoria do Discurso parte do pressuposto de que "[...] a ideologia é menos um conjunto particular de discursos do que um conjunto particular de efeitos dentro dos discursos" (MENDONÇA; RODRIGUES, p. 163).

No Capítulo 10, Multiculturalismo, pluralismo e (in) tolerância religiosa: a contribuição da Teoria do Discurso de Laclau para o debate contemporâneo, Aurenéa Maria de Oliveira destaca o processo de intolerância, ocasionado pelas reaçóes ao pluralismo - à heterogeneidade, à fragmentação das múltiplas identidades -, que tem se manifestado no mundo contemporâneo. A autora cita como exemplo "[...] o caso das reaçôes de intolerância religiosa que aconteceram entre católicos e protestantes da Irlanda do Norte e, que em 2001 culminaram na agressão por parte dos grupos protestantes a crianças 
Pós-estruturalismo e teoria do discurso: em torno de Ernesto Laclau | Fabricio Martinatto da Costa, Everton Garcia da Costa Gabriel Bandeira Coelho

católicas que iam à escola" (MENDONÇA; RODRIGUES, p. 183), além do ataque ao World Trade Center, também em 2001. Não obstante, Oliveira, em sua abordagem, elenca dois principais temas. Primeiramente, pluralismo, multiculturalismo e tolerância, discussóes sobre o lugar das diferenças em um contexto globalizado. Em um segundo momento, trata da pertinência da Teoria do Discurso de Ernesto Laclau para análise das relaçóes de tolerância/ intolerância religiosa. Nas próprias palavras de Oliveira, "[...] a concepção de Laclau de que o discurso expressa o linguístico e o extralinguístico [...] é fundamental para a análise das relaçóes de tolerância e intolerância observadas no contexto atual marcado pela globalização e pela diversidade" (MENDONÇA; RODRIGUES, p. 203).Por fim, o posfácio, escrito pelo próprio homenageado desta coletânea, Ernesto Laclau, resume, singularmente, os marcos teóricos, metodológicos e epistemológicos sobre os quais a Teoria do Discurso tem se estruturado. Nesse sentido, conforme Laclau, seu trabalho tem possibilitado a leitura política de significantes hegemônicos, como, por exemplo, os símbolos da "Solidariedade na Polônia". Mesmo que se tenha realizado uma síntese das principais ideias contidas nos artigos que compóem esta coletânea, ninguém melhor que Laclau para, de fato, definir o espírito deste trabalho. Segundo ele, "[...] os ensaios que constituem este volume desenvolvem [...] o potencial das lógicas sociais antes referidas. Considero que a expansão deste tipo de análise é fundamental para entender a constituiçáo das identidades populares da América Latina contemporânea" (MENDONÇA; RODRIGUES, p. 209).

Deve-se compreender Pós-Estruturalismo e Teoria do Discurso: em torno de Ernesto Laclau como um marco incentivador das pesquisas em relaçáo ao potencial compreensivo e prático da Teoria do Discurso. Certamente, a perspectiva de Laclau não está destinada a ser guardada no armário dos monumentos teóricos. Exemplo recente disso é a explícita convergência da teoria de Laclau com os programas políticos do Syrisa, partido de esquerda recentemente vencedor das eleiçóes gregas, e do "Podemos", partido criado na Espanha em 2014 a partir da crise de representatividade política experimentada naquele país $^{5}$. Diante disso, torna-se urgente que a academia latino-americana reúna esforços no sentido de perquirir acerca das possibilidades trazidas pela teoria laclauniana para a análise das dinâmicas sociopolíticas ocorridas no continente.

5 Ver Esquerda.net, 2015. 
A obra organizada por Daniel de Mendonça e Leo Peixoto Rodrigues é pioneira ao convergir para este importante objetivo, propondo renovar o pensamento sociopolítico político latino-americano e formular alternativas de atuação sobre o contexto social, nos seus mais diversos campos, como educação, religião, novos movimentos sociais, identidades políticas etc.

\section{Referências}

ESQUERDA.NET. Por que é Ernesto Laclau a referência intelectual do Syriza e do Podemos? 16 fev. 2015. Disponível em: <http://www.esquerda.net/artigo/por-que-e-ernesto-laclau-referenciaintelectual-do-syriza-e-do-podemos/35821>. Acesso em: 15 maio 2015.

LACLAU, E.; MOUFFE, C. Hegemony and socialist strategy: towards a radical democratic politics. London: Verso, 1985.

Recebido: 23.10.2014

Aceito: 16.03 .2015 